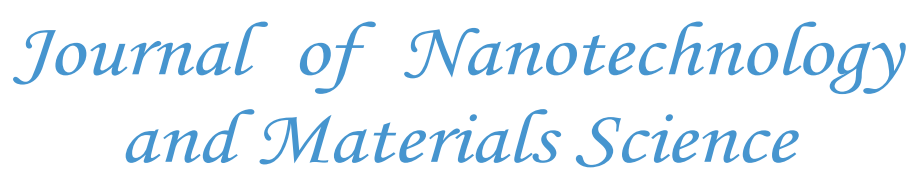

\title{
Preparation of Quantum Dots and Fluorescent Molecularly Imprinted Composite Microspheres for Determination of Tyramine
}

\author{
Yassin Haran, Chunli Li, Xingnong Zhou, Shoulei Yan* \\ College of Food Science and Technology, Huazhong Agricultural University, Wuhan, Hubei, 430070, China
}

*Corresponding author: Shoulei Yan, College of Food Science and Technology, Huazhong Agricultural University, Wuhan, Hubei, 430070, China, Tel: +18986065200; E-mail: yanshoulei1225@163.com

\begin{abstract}
The CdSe/ZnS core-shell quantum dots were prepared by using liquid paraffin as the reaction solvent and oleic acid as the modifier at a lower cost and temperature by "one-pot shelling" method. The finding of the current work showed that the UV absorption peak of the QDs was at $540 \mathrm{~nm}$ and the fluorescence emission peak was $552 \mathrm{~nm}$. The fluorescence production rate can reach up to $32.31 \%$. Also, the fluorescent molecularly imprinted composite microspheres capped with $\mathrm{CdSe} / \mathrm{ZnS}$ core-shell quantum dots were arranged in the tyramine molecularly imprinting system. Those prepared microspheres exhibited a better selective absorption ability of molecular imprinting and excellent fluorescence properties of quantum dots. It revealed a good linear relationship of the Stern-Volmer curve in the determination of tyramine, the regression equation was in $\left(F_{0} / F\right)=0.1092[\mathrm{C}]-0.0046$, which indicated that the prepared composite microspheres exhibited better performance. The above results indicate that this method is expected to achieve a fast and accurate detection of tyramine.
\end{abstract}

Keywords: Molecularly imprinted polymers; Quantum dots; Fluorescent molecularly imprinted composite microspheres; Tyramine
Received date: March 13, 2017

Accepted date: May 20, 2017

Published date: May 25, 2017

Citation: Shoulei Yan., et al. Preparation of Quantum Dots and Fluorescent Molecularly Imprinted Composite Microspheres for Determination of Tyramine. (2017) J Nanotechnol Material Sci 4(2): 32- 38.

DOI: $10.15436 / 2377-1372.17 .1419$

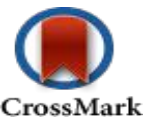

\section{Introduction}

Quantum dots (QDs) as a new kind of nanomaterial have been developed and extensively used in recent 20 years ${ }^{[1,2]}$. Since the end of the 1970s, QD (quantum dot) has attracted wide attention from physicists, chemists, and electronic engineers. In recent years, with the rapid development of nano science and technology, as well as quantum dots with unique physical and chemical properties, making them in genomics, proteomics, molecular biology, cell biology, biochemistry, drug screening, disease detection and diagnosis in the field of application expanding. QDs are a class of quasi-zero-dimensional nano crystals, which have attracted much attention from the scientific community because of their unique photoelectric properties ${ }^{[3]}$. Especially in the field of analytical testing, quantum dots as chemical sensors are widely used to detect various targets, the established fluorescence analysis method has become a satisfactory analysis and detection technology. However, the quantum dots used for fluorescence detection often face the problem of coexisting matter interference ${ }^{[4]}$, especially for the structure and performance similar to the same material detection ${ }^{[5]}$, the selectivity is not obvious, so the quantum dot fluorescence detection of specific selectivity to be further improved ${ }^{[6]}$, more for the firm and highly selective construction methods need to be developed ${ }^{[7]}$. QDs, dissimilar usual organic fluorophores, are composed of inorganic semiconducting materials, such as $\mathrm{CdSe}$, CdS, or ZnS. Compared to organic dyes, QDs are more attractive as fluorescent labels for its broad excitation spectra, which is effective to whole spectra of colors, emission without red tailing and degradation stability. Hence it offers the potential of performing multiple targets on a single sample simultaneously ${ }^{[8]}$.

Molecular Imprinting Technology(MIT) is widely used as a mature technique for the synthesis of Molecularly Imprinted 
Polymers (MIPs) with specific recognition sites ${ }^{[9]}$. The prepared molecularly imprinted polymers to have wide applicability, good plasticity, stability and high selectivity ${ }^{[10]}$. Their internal recognition sites can selectively bind to template molecules to achieve selective identification.

Nowadays, Molecularly Imprinted Polymer (MIP) technology is widely studied and developed as a strong and robust too ${ }^{[11]}$. It has a large established market and is broadly used in various fields ${ }^{[12]}$, such as separation of isomers and enantiomers $^{[13,14]}$, solid phase extraction ${ }^{[15]}$, biochemical sensor ${ }^{[16]}$, simulating enzyme-catalyzed reaction ${ }^{[17]}$, and membrane separation technology ${ }^{[18]}$. MIP prepared by traditional methods is low in binding affinity and capacity. Therefore, its application is limited. So how to prepare multifunctional composite MIP material is another hot spot of research in the field of molecular imprinting. Therefore, the combination of molecular imprinting technology and quantum dots can be used to solve the problem of poor selectivity of quantum dot fluorescence analysis. So far, the preparation method and detection technology of quantum dot molecular imprinting fluorescence sensor is relatively simple. Therefore, it is very important to improve the preparation method of high-performance quantum dot molecular imprinting fluorescence sensor and establish a new detection method ${ }^{[19]}$. MIPs and QDs technology are both polymer materials technology, which have developed over recent decades and are widely used in various fields, including the field of food safety ${ }^{[20]}$. It has been reported that the MIP-coated CdTe composites integrate the advantages of the high selectivity of the molecular imprinting and strong fluorescence property of the QDs ${ }^{[21]}$. So the new material combined the advantages of QDs and MIP will play a great role in certain fields of the small-molecule contamination detection. The synthesis of $\mathrm{CdSe} / \mathrm{ZnS}$ quantum dots with high fluorescence properties, and used it as a fluorescent sensor to successfully for determination of tyramine.

Tyramine is biogenic amines (BAs) that can induce some people's intolerant allergic reactions. It naturally existed in some food such as fermented, aged food (cured meats and cheeses) and protein breakdown, which they are most commonly considered as fermented or foods containing certain yeasts ${ }^{[22]}$. Consuming of foods containing tyramine can cause health problems such as urticaria, water retention, asthma, and the most common side effect is a migraine ${ }^{[23]}$. The level of this compound in food is related to the processing, aging, and microorganism growth.

In this paper, the CdSe quantum dots as the fluorescent carrier, the molecular imprinting technology, and sol-gel polymerization microemulsion polymerization, precipitation polymerization, swelling and surface graft copolymerization were used to prepare silicon quantum dot molecular imprinting fluorescence sensor, polymer-based quantum dots molecular imprinting fluorescence sensor and dual emission quantum dot ratio (TEM), Fourier transforms infrared absorption spectroscopy (FTIR), and other tests to study the quantum. The morphology, structure, composition and optical properties of the molecularly imprinted fluorescence sensor were studied. Combined with the fluorescence recognition experiment, the molecular detection of the target molecule by molecular imprinting fluorescence sensor is discussed in detail. The selective identification energy force and recognition mechanism.

In this study, $\mathrm{CdSe} / \mathrm{ZnS}$ core-shell QDs in oleic acid - liquid paraffin reaction system was synthesized. Then, the assessment of morphology, composition and optical properties were characterized by FT-IR and fluorescence spectrophotometer, XRD TEM. Tyramine was used as a template molecule and $\mathrm{CdSe} / \mathrm{ZnS}$ core-shells QDs as a label as to create fluorescent molecular imprinted composite microspheres for the detection of tyramine.

\section{Materials and Methods}

\section{Reagents}

2, 2-Azobis (2, 4-dimethyl valeronitrile), liquid paraffin, oleic acid (OA,98.5\%) and glacial acetic acid (99.7\%) were obtained from Sinopharm Group (China), in chemical grade. Methacrylic acid (MAA, 95.0\%) and ethylene glycol dimethacrylate (EGDMA, 98.0\%) were purchased from Sigma-Aldrich (Shanghai, China), it used without further purification. Selenium powder ( $\mathrm{Se}, 99.9 \%)$, sulfur powder $(95.0 \%)$, zinc oxide $(\mathrm{ZnO}$, 94.0\%), cadmium oxide (CdO, 99.0\%), acetonitrile ( $\mathrm{ACN}$, 99.0\%, HPLC grade), Methanol (MeoH, 98.8\%, HPLC grade), toluene (Sinopharm, $97.0 \%$ ) , acetone $(90.0 \%)$, petroleum ether (ACS grade, $99.0 \%$ ), tyramine $(98.0 \%)$, and rhodamine $(98.0 \%)$ were all purchased from Sinopharm Group, in analytical grade. And tyramine (Shanghai crystal pure reagent Co., Ltd, China) was used as the template molecule. Double distilled water was used in all experiments.

\section{Apparatus}

The spectrophotometric measurements were made with a UV-1700 spectrophotometer (SHIMADZU, Japan), Fluorescence spectrophotometer (SHIMADZU, Japan) and Infrared spectrometer (NICDET, America). The JE high-speed refrigerated centrifuge (BECKMAN, America), DF-101S collector thermostat heating the magnetic stirrer (Zhengzhou Great Wall Branch Industry and Trade Co., Ltd) and WD-9403C type ultraviolet analyzers (Beijing Six-one Instrument Factory, China) were used during the experiment. Electrically heated water bath (Jiangsu Guohua Instrument Factory, China) was used for controlling temperature.

\section{Methods}

\section{Preparation of CdSe/ZnS core-shell QDs}

The method was referred to "one-pot shelling"[24]. Figure 1 and Figure 2 showed the preparing procedure and devices.

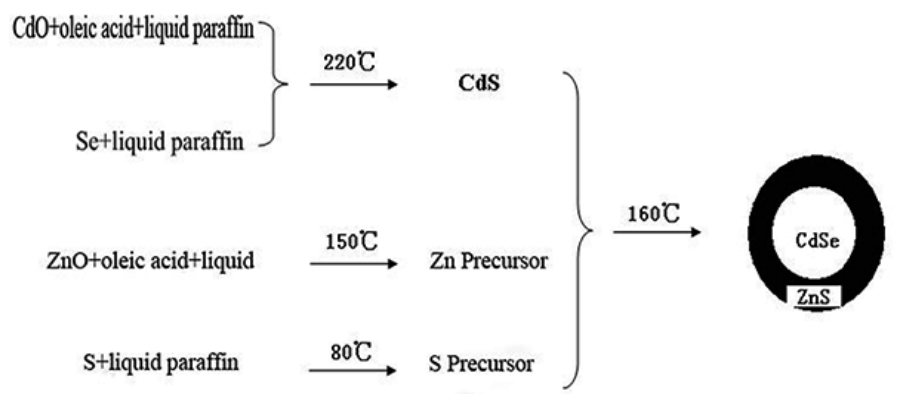

Figure 1: The preparation flow chart of $\mathrm{CdSe} / \mathrm{ZnS}$. 


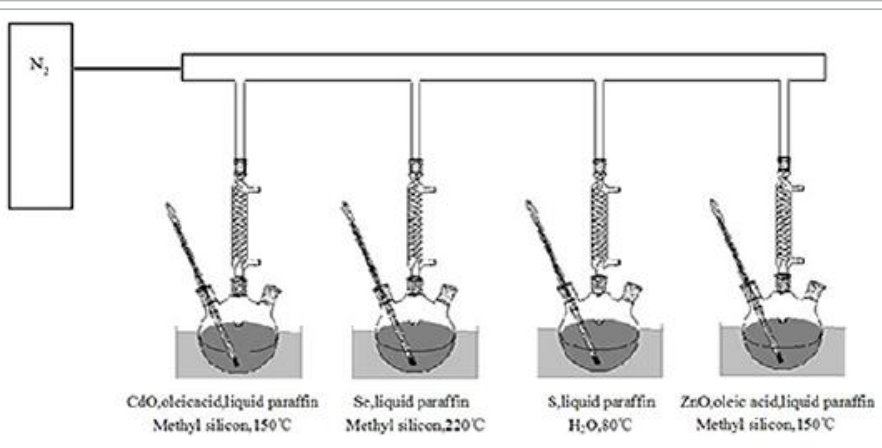

Figure 2: The synthesis device of "one-pot shelling".

Calculation of fluorescence quantum yield of $\mathrm{CdSe} / \mathrm{ZnS}$

The fluorescence quantum yield of $\mathrm{CdSe} / \mathrm{ZnS}$ was calculated according to the following equation ${ }^{[25]}$ :

$Q Y_{u}=Q Y_{s} \times F_{u} / F_{s} \times A_{s} / A_{u}$

Where $Q Y_{u^{\prime}} Q Y_{s}$ is the fluorescence quantum yield of sample and Rhodamine respectively, $A_{u^{\prime}} A_{s}$ is the Absorbance at a fixed excitation wavelength of the incident light of sample and Rhodamine; $F_{u}, F_{s}$ is the integral of the fluorescence intensity of the sample and Rhodamine.

\section{Optical properties and structure analysis of $\mathrm{CdSe} / \mathrm{ZnS}$}

A right amount of $\mathrm{CdSe} / \mathrm{ZnS}$ quantum dots was dissolved in toluene to form a homogeneous solution, to determine the ultraviolet absorption spectra and fluorescence emission spectra at an appropriate wavelength respectively. Furthermore, the infrared spectrometer was used to analyze the infrared spectra of $\mathrm{CdSe} / \mathrm{ZnS}$ core-shell quantum dots.

\section{Preparation of fluorescent molecularly imprinted composite microspheres}

$1 \mathrm{~mL} \mathrm{CdSe} / \mathrm{ZnS}$-toluene solution $(3 \mathrm{mg} / \mathrm{mL}), 137 \mathrm{mg}$ tyramine, $0.34 \mathrm{~mL}$ MAA, $50 \mathrm{~mL}$ acetonitrile were added into a round-bottom flask, then the mixture was ultrasonicated to make tyramine dissolve completely. Put the flask in $4^{\circ} \mathrm{C}$ refrigerators for overnight, and afterwards add $3.8 \mathrm{~mL}$ EGDMA, 40 $\mathrm{mg}$ AIBN to the mixture. After oscillation and deoxygenating, the flask was sealed completely, and placed at $\lambda=365 \mathrm{~nm}$ ultraviolet to initiate for $6 \mathrm{~h}$, then the flask was warmed for $18 \mathrm{~h}$ at 60 ${ }^{\circ} \mathrm{C}$. To ensure complete cross-linking, the final solution was ultrasonicated to form a homogeneous emulsion and centrifugated at $5000 \mathrm{rpm}$ for $30 \mathrm{~min}$, and then the supernatant was discarded. The polymers were washed with acetonitrile and extracted with a glacial acetic acid-methanol solution $(6: 4 \mathrm{v} / \mathrm{v})$ and then followed by washing with methanol, dried in an oven at $40{ }^{\circ} \mathrm{C}$, and the fluorescent molecular imprinted composite microspheres were obtained ${ }^{[26]}$.

Optical properties and structure characterization of fluorescent molecularly imprinted composite microspheres

A right amount of fluorescent molecular imprinted composite microspheres was dissolved in toluene to form a homogeneous solution, to determine the ultraviolet absorption spectra and fluorescence emission spectra at an appropriate wavelength respectively. Furthermore, the infrared spectrometer was used to analyze the infrared spectra of fluorescent molecular imprinted composite microspheres.
Fluorescence quenching to fluorescence molecular imprinting microspheres by tyramine

The fluorescent molecular imprinted composite microspheres were ground and accurately weighed into a group of the container, and then the different concentration of tyramine acetonitrile solution was added respectively to measure their fluorescence intensity at a proper excitation wavelength.

\section{Transmission Electron Microscopy (TEM)}

The Transmission Electron Microscopy (TEM) studies were performed on an FEI Tecnai TF20 is a $200 \mathrm{kV}$ FEG high-resolution Transmission Electron Microscope (TEM). The samples were prepared by placing a few microliters of precipitated, washed, vacuum dried, and the sample redissolved in toluene solution into a carbon-coated formvar copper grid, and the grids were allowed to dry overnight $\mathrm{CdSe} / \mathrm{ZnS}$ core-shell quantum dots $(\mathrm{CdSe})$.

\section{Powder X-Ray Diffraction( PXRD)}

XRD studies were performed using A (Bruker D8 Advance X-Ray Diffractometer) was employed to determine $\mathrm{CdSe} / \mathrm{ZnS}$ core-shell quantum dots and electronic structure. The solution samples of CdSe quantum dots, $\mathrm{CdSe} / \mathrm{ZnS}$ core-shell structure quantum dots were centrifuged and the solid powders obtained by vacuum drying were subjected to XRD test. Powder $\mathrm{X}$-ray diffraction analysis of the samples were carried out on a Bruker D8 Advance diffractometer using Ni-filtered, $\mathrm{Cu} \mathrm{K \alpha}$ radiation $(\lambda=0.15418 \mathrm{~nm})$.

\section{Results and Discussion}

\section{Preparation of CdSe/ZnS core-shell QDs}

CdSe quantum dots are most commonly used for the biomarkers field. The fluorescence emission range is very broad, including the visible region. However, CdSe quantum dots have some defects as we all know. First of all, CdSe quantum dot was stored in organic reagents such as hexane, chloroform, and toluene in the refrigerator or a dark room ${ }^{[27]}$, because it is unstable and susceptible to oxidation. Secondly, the surface of CdSe quantum dot has a lot of defects, which will affect the quantum yield. Finally, quantum dots are synthesized mostly by toxic heavy-metal elements, so its application is limited ${ }^{[28]}$.

In general, quantum dots surface can wrap organic layer to maintain temporary stability, and such treatment will not make much difference to its characteristic absorption. However, the surface properties of the quantum dots will have an impact on its structure and optical properties. So the modification of quantum dots surface is of vital importance. Actually, we generally wrap other semiconductor materials around the quantum dots to form a core-shell structure which can enhance its fluorescence quantum yield, and weaken its biological toxicity, to overcome the defects on its essence and promote its application.

The CdSe/ZnS core-shell QD was first proposed in 1990 by some experts and scholars ${ }^{[2,30]}$. In order to further improve the quantum yield of QDs, the wide-band gap semiconductor material with a similar crystal structure is usually formed on its surface, and the core-shell structure is formed. Therefore, based on the synthesis of CdSe QD, we prepared CdSe/Zns QD. We combine molecularly imprinted technology with the quantum dots technology to prepare fluorescent molecularly imprint- 
ed composite microspheres for determination of tyramine. By constant practice and application, a set of new methods which can obtain the uniform size and high quantum yield core-shell quantum dots were developed. A $\mathrm{CdS} / \mathrm{CdZnS} / \mathrm{ZnS}$ multi-layer inorganic shell was developed using a yield core-shell meth$\mathrm{od}^{[31-36]}$. In this experiment, the precursor of various metal elements was made of $\mathrm{CdO}, \mathrm{ZnO}, \mathrm{S}$ powder and Se powder, then $\mathrm{CdSe} / \mathrm{ZnS}$ core-shell quantum dots were prepared in oleic acid-liquid paraffin reaction system.

\section{Optical properties and structure characterization of $\mathrm{CdSe}$ / $\mathrm{ZnS}$}

The first requirement for the application of quantum dots is that its optical properties should be in accord with our need. We have measured the absorption spectra and fluorescence spectra of $\mathrm{CdSe} / \mathrm{ZnS}$ core-shell quantum dots, as shown in Figure 3. UV-visible absorption spectra, FT-IR spectra, X-Ray Diffraction (XRD) and Transmission Electron Microscopy (TEM) are used to identify and characterization of $\mathrm{CdSe} / \mathrm{ZnS}$.

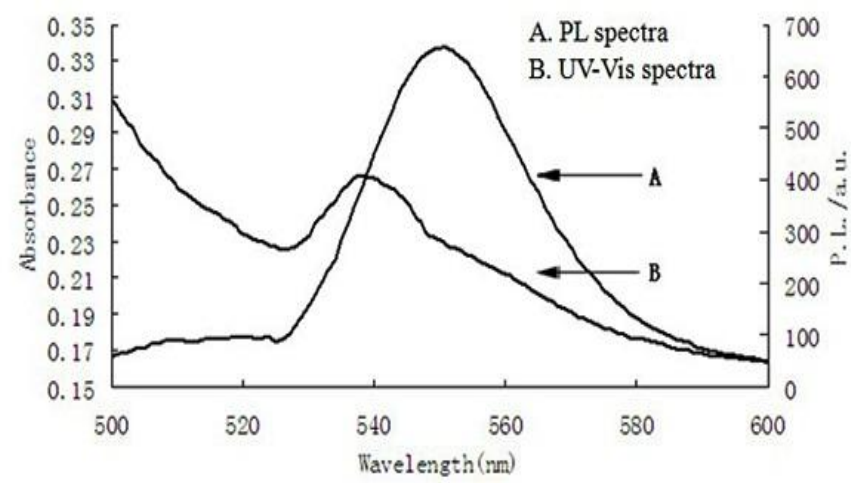

Figure 3: The UV-Vis spectra and PL spectra of CdSe/ZnS.

\section{TEM analysis of $\mathrm{CdSe} / \mathrm{ZnS}$}

The Transmission Electron Microscopy (TEM) studies were performed on an FEI Tecnai TF20 is a $200 \mathrm{kV}$ FEG high-resolution Transmission Electron Microscope (TEM). The samples were prepared by placing a few microliters of precipitated, washed, vacuum dried, and the sample redissolved in toluene solution into a carbon-coated formvar copper grid, and the grids were allowed to dry overnight $\mathrm{CdSe} / \mathrm{ZnS}$ core-shell [n quantum dots $(\mathrm{CdSe})$ : and $(\mathrm{ZnS})=1: 4]$. The detail of the experimental arrangement of TEM test shown in Figure 4(a,b) the Transmission Electron Microscopy (TEM) photographs of CdSe, CdSe/ $\mathrm{ZnS}$, and the finally obtained $\mathrm{CdSe} / \mathrm{ZnSe} / \mathrm{ZnS}$ care-shell quantum dots. It can be seen that the grains are close to spherical, and the initial CdSe average particle size is about the average particle size of the $\mathrm{ZnSe}$ shell is about $1 \mathrm{~nm}$ after one step of direct growth of $\mathrm{ZnSe}$ shell. After the growth of $\mathrm{ZnS}$ shell, the average particle size increases to $5 \mathrm{~nm}$, and the quantum particle size increases gradually. The surface of the inorganic shell grows.
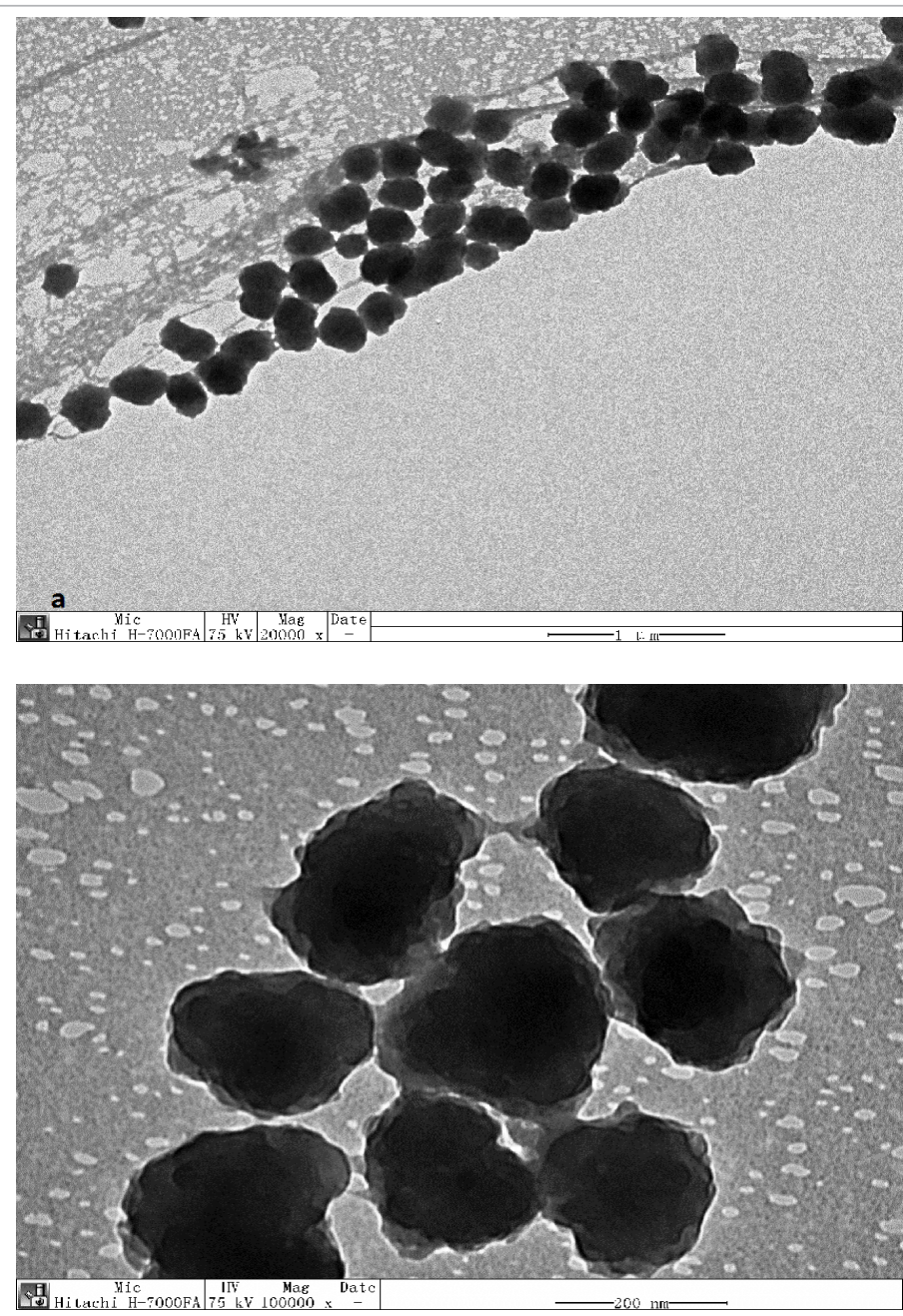

Figure 4: The TEM image of $\mathrm{CdSe}$ and $\mathrm{CdSe} / \mathrm{ZnS}$ core-shell quantum dosts (QDs).

\section{XRD analysis of CdSe/ZnS}

XRD studies were performed using A (Bruker D8 Advance X-Ray Diffractometer) was employed to determine $\mathrm{CdSe} / \mathrm{ZnS}$ core-shell quantum dots and electronic structure. The solution samples of $\mathrm{CdSe}$ quantum dots, $\mathrm{CdSe} / \mathrm{ZnS}$ core-shell structure quantum dots were centrifuged and the solid powders obtained by vacuum drying were subjected to XRD test. Powder $\mathrm{X}$-ray diffraction analysis of the samples were carried out on a Bruker D8 Advance diffractometer using Ni-filtered, $\mathrm{Cu} \mathrm{K \alpha}$ radiation $(\lambda=0.15418 \mathrm{~nm})$. The diffractometer was operated at a tube voltage of $40 \mathrm{kV}$ and a current of $40 \mathrm{mAe}$ with 10 degrees/ minute, a step size of $0.022 \theta$. The X-Ray Diffraction (XRD) pattern of the core-shell structure material formed by the anisotropic mode will have the phenomenon of the diffraction peak shift with the outer layer. Therefore, it is possible to determine whether the surface $\mathrm{CdS}$ covers the other material by the XRD pattern material. Figure 5 shows the XRD patterns of CdSeQDs and CdSe/ZnSQDs, $25.6^{\circ}$ for 111 crystal faces, $42.4^{\circ}$ for 220 crystal faces, and $49.2^{\circ}$ for 311 crystal planes, which coincides with the peak pattern of sphalerite. 


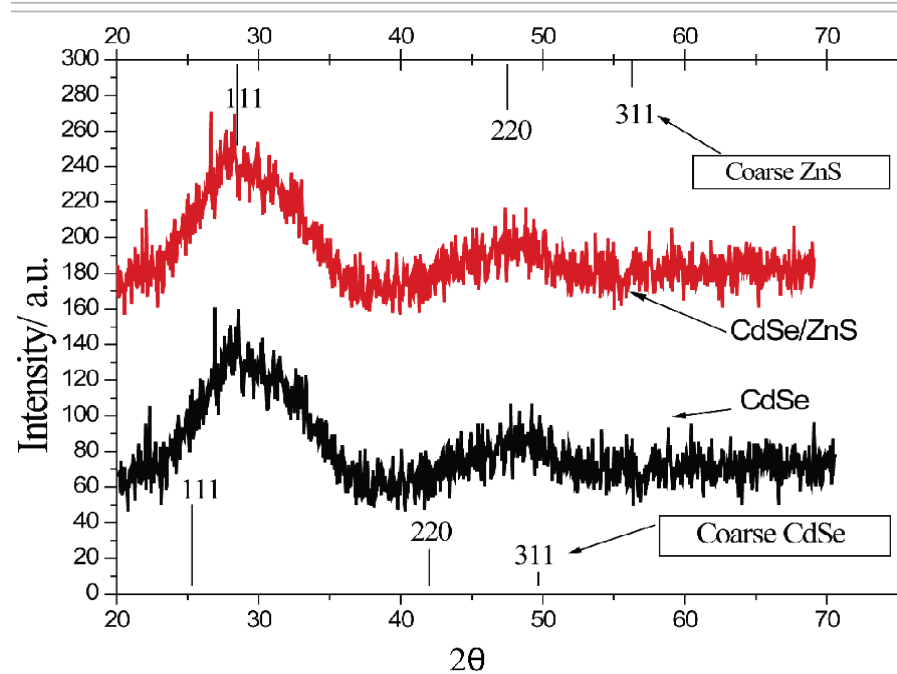

Figure 5: The XRD patterns of $\mathrm{CdSe}$ and $\mathrm{CdSe} / \mathrm{ZnS}$ core-shell quantum dosts (QDs).

\section{FT-IR analysis of $\mathrm{CdSe} / \mathrm{ZnS}$}

Figure 6 shows the IR spectra of $\mathrm{CdSe} / \mathrm{ZnS}$ quantum dots. According to the spectra, the presence of the bands around $3400 \mathrm{~cm}^{-1}$ was the $\mathrm{OH}$ stretching vibration band; the bands at $2850 \mathrm{~cm}^{-1}$ and $2920 \mathrm{~cm}^{-1}$ were the $\mathrm{C}-\mathrm{H}$ stretching vibration, $\mathrm{CH}$ bending vibration peak is near $1380 \mathrm{~cm}^{-1}$, the absorption peak around $1620 \mathrm{~cm}^{-1}$ is the stretching vibration of the $\mathrm{C}=\mathrm{C}$ group, suggesting the oleic acid group was successfully modified onto the surface of the QDs, and $710 \mathrm{~cm}^{-1}$ are typical of CdSe characteristic vibration peak. Further evidence from the treatment shows that the CdSe core was thoroughly passivation by a layer of $\mathrm{ZnS}$ shell.

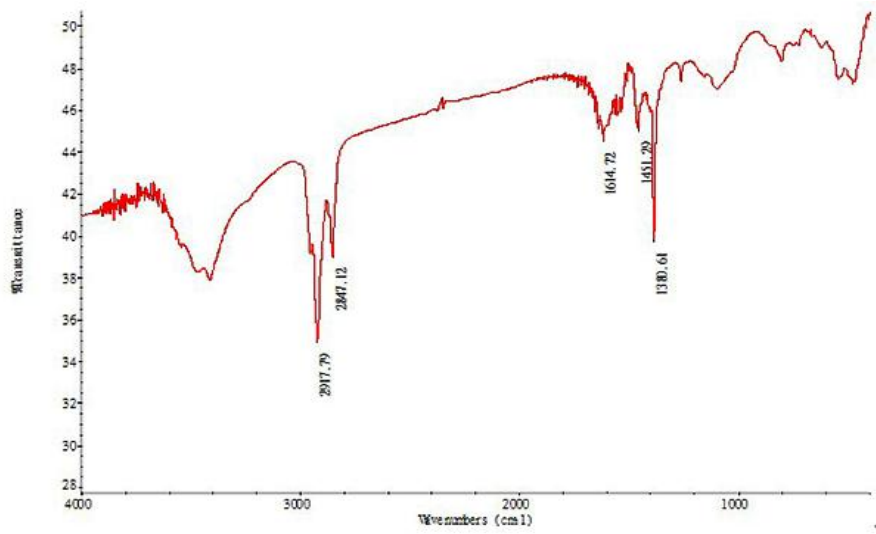

Figure 6: The IR spectra of CdSe/ZnS.

\section{Optical properties and structure characterization of fluores-} cent molecular imprinted composite microspheres

In this experiment, fluorescent molecular imprinted composite microspheres were synthesized in situ polymerization method. The solution of the quantum dots should be good homogeneity and chemical properties should be of relatively stability when adopting such method. Generally, the quantum dots were modified by introducing a number of other groups on the surface. So in the experiment, we added oleic acid to achieve this effect.

Figure 7 is the fluorescence spectra of fluorescent molecule imprinting composite microspheres. Compared with $\mathrm{CdSe} /$ $\mathrm{ZnS}$ core-shell quantum dots, the fluorescence intensity of flu- orescent molecule imprinting composite microspheres is weaker, peak type is broadened and absorption peak is uneven. The reason may be that the content of $\mathrm{CdSe} / \mathrm{ZnS}$ core-shell quantum dots is low, and the molecularly imprinted layer package is too thick.

Figure 8 is the infrared spectra of fluorescent molecular imprinted composite microspheres. Compared with Figure 4 , some new strong peaks, such as $1720 \mathrm{~cm}^{-1}(\mathrm{C}=\mathrm{O}$ stretch) and $1150 \mathrm{~cm}^{-1}$ (C-O stretch) were shown up. The stretching vibration at $1720 \mathrm{~cm}^{-1}$ was recognized to $\mathrm{COOH}$ of MAA. The stretching vibration $\mathrm{C}=\mathrm{O}\left(1720 \mathrm{~cm}^{-1}\right)$ and an increase of $\mathrm{C}-\mathrm{O}-\mathrm{C}\left(1150 \mathrm{~cm}^{-}\right.$ $\left.{ }^{1}\right)$ peak intensity revealed the existence of EGDMA. In addition, the $\mathrm{CdSe} / \mathrm{ZnS}$ and fluorescent molecule imprinting composite microspheres showed similar locations and appearance of the major bands, such as $3400 \mathrm{~cm}^{-1}$ (OH stretch), $1620 \mathrm{~cm}^{-1}(\mathrm{C}=\mathrm{O}$ stretch), $1380 \mathrm{~cm}^{-1}$ (CH bend), which was because some compositions between $\mathrm{CdSe} / \mathrm{ZnS}$ and fluorescent molecule imprinting composite microspheres were similar. So the molecularly imprinted polymer has been successfully synthesized on the surface of $\mathrm{CdSe} / \mathrm{ZnS}$ core-shell QD.

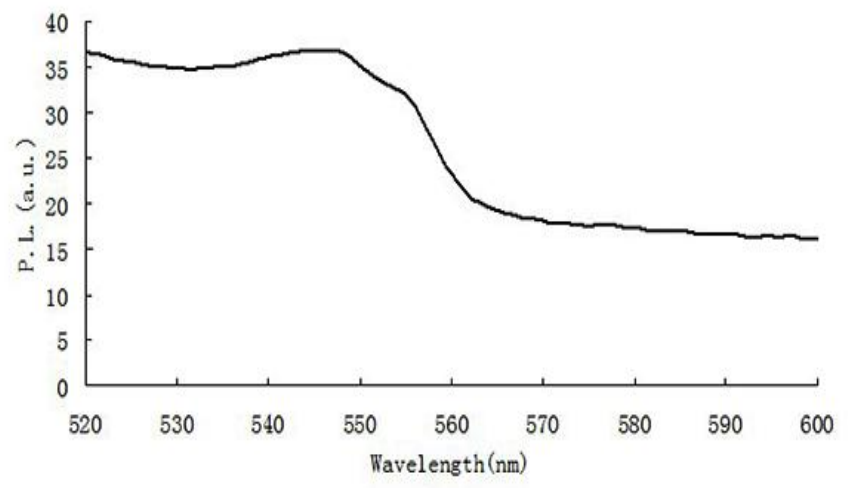

Figure 7: The PL spectra of composite microspheres.

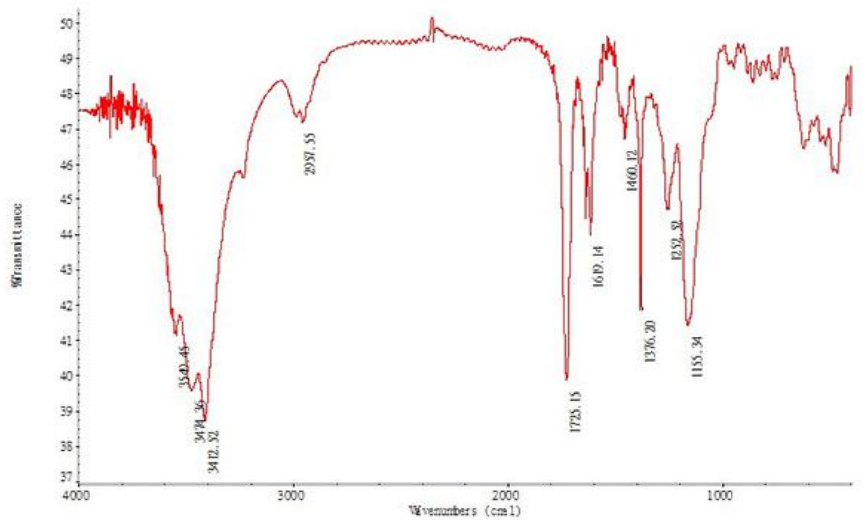

Figure 8: The IR spectra of composite microspheres.

Fluorescence quenching to fluorescence molecular imprinting microspheres by tyramine

The quantum dot surface structure has a certain relationship between fluorescence intensity and stability, and it is vulnerable to be affected by the external environment and leads to physical and chemical properties changes, as a result, the fluorescence emission property changes. As shown in Figure 9, when tyramine fluorescence molecular imprinting composite microspheres encountered tyramine, the adsorption effect of ty- 
ramine on fluorescence molecular imprinting microspheres was shown through the fluorescence intensity decrease. We found that, by adding different concentrations of tyramine solution in the same quality composite microspheres. The fluorescence intensity decreased with increasing concentration of tyramine, which indicates that tyramine can quench the fluorescence of the composite microspheres to some extent.

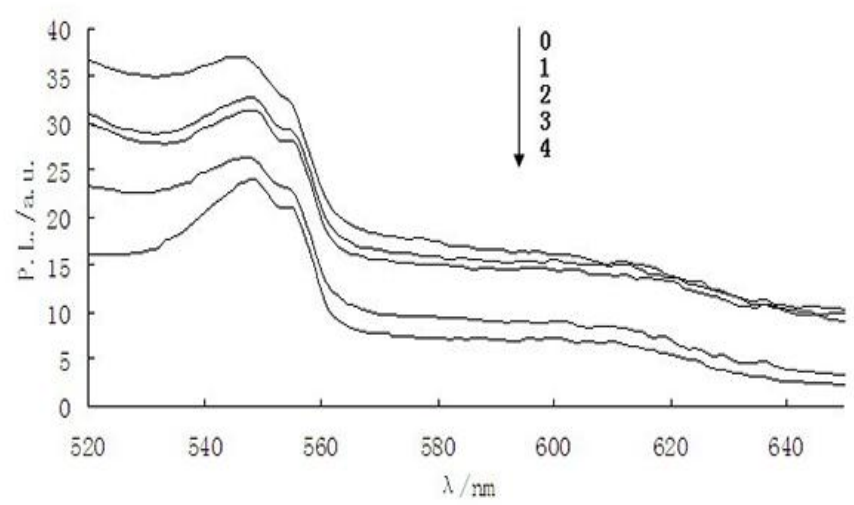

Figure 9: The PL spectra of composite microspheres at various concentrations $(0 \mathrm{mmol} / \mathrm{L}, 1 \mathrm{mmol} / \mathrm{L}, 2 \mathrm{mmol} / \mathrm{L}, 3 \mathrm{mmol} / \mathrm{L}, 4 \mathrm{mmol} / \mathrm{L})$ of tyramine.

No matter, it is dynamic or static quenching or the two fluorescence quenching effects both exist; it follows the Stern-Volmer equation. The modified Stern-Volmer equation ${ }^{[37]}$ is as follows:

$\ln \left(F_{0} / F\right)=K_{S V}[C]-K$

Fluorescence intensity before and after thee; i coconstant; s concentration; $K_{S V}$ is Quenching constant. It is quenching ws, a good linear relationship is presented in sight, and the regression equation is $\ln \left(F_{\delta} / F\right)=0.1092[\mathrm{C}]-0.0046$, in all, each data consistently shows good performance of the prepared composite microspheres. And further work will be done, like the application for real samples.

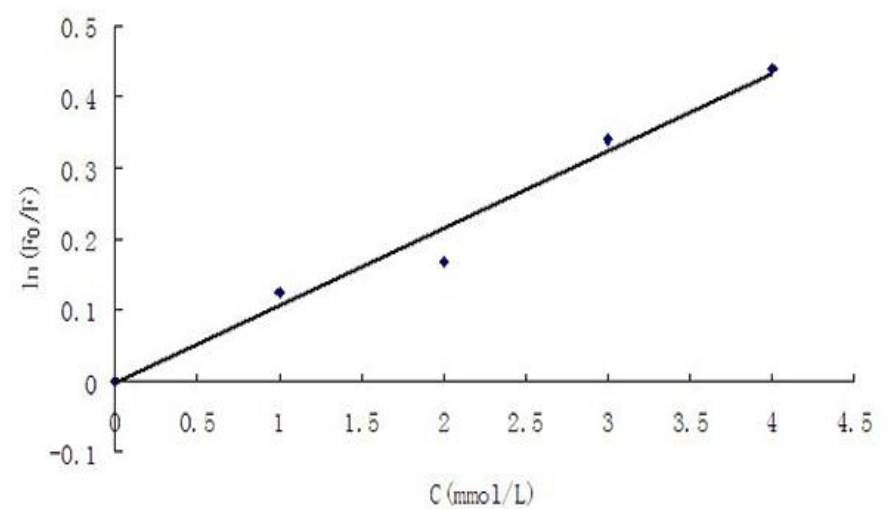

Figure 10: The Stern-Volmer plot for composite microspheres with tyramine.

\section{Conclusion}

This experiment was conducted in the high temperature of $220^{\circ} \mathrm{C}$ reaction's solvent-liquid paraffin, high-quality $\mathrm{CdSe} /$ $\mathrm{ZnS}$ core-shell quantum dots were synthesized with oleic acid as the stable mixture by using the "one-pot shelling" method on the condition that the reaction can be controlled. The absorption peak of UV-visible absorption spectra was at $540 \mathrm{~nm}$, the quantum dot fluorescence emission peak wavelength located near $552 \mathrm{~nm}$ when the excitation wavelength was $391 \mathrm{~nm}$, and the fluorescence yield was up to $32.31 \%$. By adding $\mathrm{CdSe} / \mathrm{ZnS}$ coreshell quantum dots to tyramine molecular imprinting system, the fluorescent molecular imprinting composite microspheres were prepared. The good selectivity of molecular imprinting and excellent fluorescence properties of quantum dots were well exhibited in the microspheres. In the analytical detection of tyramine, Stern-Volmer curve showed a good linear relationship. The regression equation was $\ln \left(F_{d} / F\right)=0.1092[\mathrm{C}]-0.0046$. This indicated the good performance of the prepared composite microspheres. It is promising to achieve the fast and accurate detection of tyramine.

\section{Acknowledgement}

Financial support from the National Natural Science Foundation of China (No.31000782) through the Youth Science Fund Project and Natural Science Foundation of Hubei Province of China (No. 2009CDD214) are gratefully acknowledged.

\section{References}

1. Zhao, M.X., Zeng, E.Z. Application of functional quantum dot nanoparticles as fluorescence probes in cell labeling and tumor diagnostic imaging. (2015) Nanoscale Res Lett 10: 171.

Pubmed|Crossref|Others

2. Bonilla, C.A.M., Kouznetsov, V.V. "Green” Quantum Dots: Basics, Green Synthesis, and Nanotechnological Applications, in Green Nanotechnology-Overview and Further Prospects. (2016) InTech.

Crossref| Others

3. Richter, M., Heumüller, T., Matt, G.J., et al. Carbon Photodetectors: The Versatility of Carbon Allotropes. (2016) Adv Energy Mat.

Crossref $\mid$ Others

4. Ke, J., Li, X., Zhao, Q., et al. Ultrasensitive quantum dot fluorescence quenching assay for selective detection of mercury ions in drinking water. (2014) Sci Rep 4: 5624.

Pubmed | Crossref|Others

5. Deerinck, T.J. The application of fluorescent quantum dots to confocal, multiphoton, and electron microscopic imaging. (2008) Toxicol pathol 36(1): 112-116.

Pubmed | Crossref

6. Yan, Y., Wang, S., Liu, Z., et al. CdSe-ZnS quantum dots for selective and sensitive detection and quantification of hypochlorite. (2010) Anal chem 82(23): 9775-9781.

Pubmed | Crossref| Others

7. Zhou, R., Zhao, Q., Liu, K.K., et al. Europium-decorated ZnO quantum dots as a fluorescent sensor for the detection of an anthrax biomarker. (2017) J Mater Chem C 5(7): 1685-1691.

Crossref|Others

8. Lin, C.I., Joseph, A.K., Chang, C.K., et al. Molecularly imprinted polymeric film on semiconductor nanoparticles analyte detection by quantum dot photoluminescence. (2004) J Chromatogr A 1027(1-2): 259-262.

Pubmed | Crossref | Others

9. Chen, L., Wang, X., Lu, W., et al. Molecular imprinting: perspectives and applications. (2016) Chem Soc Rev 45(8): 2137-2211.

Pubmed | Crossref | Others

10. Lee, S., Lin, O.H., Doong, R. Design of size-tunable molecularly imprinted polymer for selective adsorption of acetaminophen. (2017) Clean Technol Env Policy 19(1): 243-250.

Crossref $\mid$ Others 
11. Del Blanco, S.G., Donato, L., Drioli, E. Development of molecularly imprinted membranes for selective recognition of primary amines in organic medium. (2012) Sep Purification Technol 87: 40-46.

Crossref|Others

12. Wang, H.Y., Jiang, J.G., Ma, L.Y., et al. Syntheses of molecularly imprinted polymers and their molecular recognition study for benzotriazole. (2006) React Func Polymers 66(10): 1081-1086.

Crossref|Others

13. Yin, J., Yang, G., Chen, Y. Rapid and efficient chiral separation of nateglinide and its L-enantiomer on monolithic molecularly imprinted polymers. (2005) J Chromatogr A 1090(1-2): 68-75.

Pubmed |Crossref | Others

14. Aboul-Enein, H.Y., El-Awady, M.I., Heard, C.M. Direct enantiomeric resolution of some cardiovascular agents using synthetic polymers imprinted with (-)-S-timolol as chiral stationary phase by thin layer chromatography. (2002) Pharmazie 57(3): 169-171.

Pubmed | Others

15. Gholivand, M.B., Khodadadian, M., Ahmadi, F. Computer aided-molecular design and synthesis of a high selective molecularly imprinted polymer for solid-phase extraction of furosemide from human plasma. (2010) Anal Chim Acta 658(2): 225-232.

Pubmed | Crossref | Others

16. Fang, Y., Yan, S., Ning, B., et al. Flow injection chemiluminescence sensor using molecularly imprinted polymers as recognition element for determination of maleic hydrazide. (2008) Biosens Bioelectron 24(8): 2323-2327.

Pubmed |Crossref | Others

17. Lettau, K., Katterle, M., Warsinke, A., et al. Sequential conversion by catalytically active MIP and immobilized tyrosinase in a thermistor. (2008) Biosens Bioelectron 23(7): 1216-1219.

Pubmed | Crossref| Others

18. Ulbricht, M. Membrane separations using molecularly imprinted polymers. (2004) J Chromatogr B 804(1): 113-125.

Pubmed | Crossref| Others

19. Gao, X., Hu, X., Guan, P., et al. Synthesis of core-shell imprinting polymers with uniform thin imprinting layer via iniferter-induced radical polymerization for the selective recognition of thymopentin in aqueous solution. (2016) RSC Advances 6(111): 110019-110031.

Crossref| Others

20. Song, X., Xu, S., Chen L., et al. Recent advances in molecularly imprinted polymers in food analysis. (2014) J Appl Polymer Sci 131(16). Crossref|Others

21. Zhang, W., He, X.W., Chen, Y., et al. Composite of CdTe quantum dots and molecularly imprinted polymer as a sensing material for cytochrome c. (2011) Biosens Bioelectron 26(5): 2553-2558.

Pubmed | Crossref | Others

22. Żukiewicz-Sobczak, W.A., Wróblewska, P., Adamczuk, P., et al. Review paper Causes, symptoms and prevention of food allergy. (2013) Postępy Dermatol Alergol 30(2): 113-116.

Pubmed | Crossref | Others

23. Headquarters, FAO. Joint FAO/WHO Expert Meeting on the Public Health Risks of Histamine and Other Biogenic Amines from Fish and Fishery Products. (2012).

Others

24. Liao, Y., Li, W. Synthesis of CdSe quantum dots via paraffin liquid and oleic acid. (2008) J Zhejiang Univers-Sci A 9(1): 133-136.

Crossref|Others
25. Zhao, J., Wei, Y.J. Fluorescence spectra and fluorescence quantum yield of triton X-100. (2006) 26(8): 1523-1525.

Pubmed | Others

26. Yang, W.H., Wu, Y., Zhang, Y., et al. Preparation and Application of Core-Shell Magnetic Molecularly Imprinted Polymer Microspheres. (2010) Prog Chem 22(9): 1819-1825.

Others

27. He, R., You, X., Tian, H., et al. Synthesis and characterization of monodisperse CdSe quantum dots in different organic solvents. (2006) Front Chem China 1(4): 378-383.

Crossref |Others

28. Ge, M., Yue, Y., Liu, Y., et al. Facile capping CdS and ZnS shells by thermolysis of ethylxanthate precursors for $\mathrm{CdSe} / \mathrm{CdS} / \mathrm{ZnS}$ nanocrystals. (2011) Colloids and Surfaces A: Physicochem Eng Aspects 384(1-3): 574-579.

Crossref |Others

29. Wei, H., Zhou, J., Zhang, L., et al. The core/shell structure of CdSe/ $\mathrm{ZnS}$ quantum dots characterized by X-ray absorption fine spectroscopy. (2015) J Nanomater 2015(3): 1-7.

Others

30. Bawendi, M.G., Steigerwald, M.L., Brus, L.E. The quantum mechanics of larger semiconductor clusters ("quantum dots"). (1990) Annual Rev Phy Chem 41(1): 477-496.

Crossref|Others

31. Talapin, D.V., Mekis, I., Götzinger, S., et al. CdSe/CdS/ZnS and $\mathrm{CdSe} / \mathrm{ZnSe} / \mathrm{ZnS}$ core-shell-shell nanocrystals. (2004) J Phys Chem B 108(49): 18826-18831.

Crossref| Others

32. Xie, R., Kolb, U., Li, J., et al. Synthesis and characterization of highly luminescent $\mathrm{CdSe}-\mathrm{Core} \mathrm{CdS} / \mathrm{Zn}_{0.5} \mathrm{Cd}_{0.5} \mathrm{~S} / \mathrm{ZnS}$ multishell nanocrystals. (2005) J Am Chem Soc 127(20): 7480-7488.

Pubmed | Crossref | Others

33. Li, J.J., Wang, Y.A., Guo, W., et al. Large-scale synthesis of nearly monodisperse $\mathrm{CdSe} / \mathrm{CdS}$ core/shell nanocrystals using air-stable reagents via successive ion layer adsorption and reaction. (2003) J Am Chem Soc 125(41): 12567-12575.

Pubmed | Crossref | Others

34. Drijvers, E., Roo, J.D., Geiregat, P., et al. Revisited Wurtzite CdSe Synthesis: A Gateway for the Versatile Flash Synthesis of Multishell Quantum Dots and Rods. (2016) Chem Mater 28(20): 7311-7323.

Crossref |Others

35. Ahamefula, C., Sulaimanet, M.Y., Ibarahim, Z., et al. Synthesis and Characterization of CdSe Quantum Dot via Pyrolysis of Organometalic Reagent. (2011).

Others

36. Karim, M., Ferdous, Z., Ünlü, H. Synthesis and Optical Characteristics of CdSe/ZnS core/shell Nanocrystals. (2014).

Pubmed | Crossref $\mid$ Others

37. Sun, J.F., Liu, L., Ren, C., et al. A feasible method for the sensitive and selective determination of vitamin $\mathrm{B} 1$ with $\mathrm{CdSe}$ quantum dots. (2008) Microchimica Acta 163(3): 271-276.

Crossref $\mid$ Others
Ommega Online Publishers

Journal Title: Journal of Nanotechnology and Materials Science Journal Short Name: J Nanotech Mater Sci
Journal ISSN: 2377-1372

E-mail: nanoscience@ommegaonline.com

Website: www.ommegaonline.org 